\title{
Estimation of forest structural and compositional variables using ALS data and multi-seasonal satellite imagery
}

Shang, Chen \& Treitz, Paul \& Caspersen, John \& Jones, Trevor

Version Post-print/Accepted Manuscript

Citation Shang, C., Treitz, P., Caspersen, J., \& Jones, T. (2019). Estimation of

(published version) forest structural and compositional variables using ALS data and multiseasonal satellite imagery. International Journal of Applied Earth Observation and Geoinformation. 78, 360-371.

$\underline{10.1016 / \text { i.jag.2018.10.002. }}$

Copyright/License

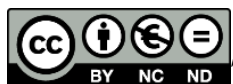

(c) ${ }_{\text {BY }}$ ND This work is licensed under the Creative Commons

Attribution-NonCommercial-NoDerivatives 4.0 International License.

To view a copy of this license, visit Creative Commons BY NC ND 4.0 License.

How to cite TSpace items

Always cite the published version, so the author(s) will receive recognition through services that track citation counts, e.g. Scopus. If you need to cite the page number of the author manuscript from TSpace because you cannot access the published version, then cite the TSpace version in addition to the published version using the permanent URI (handle) found on the record page.

This article was made openly accessible by $U$ of $T$ Faculty. Please tell us how this access benefits you. Your story matters. 
1 Estimation of forest inventory variables using ALS data and multi-

2 seasonal satellite imagery

3 Chen Shang ${ }^{a}$, Paul Treitz ${ }^{a}$, John Caspersen ${ }^{b}$, Trevor Jones

4 a Department of Geography and Planning, Queen's University, Kingston, ON, K7L 3N6,

5 Canada

$6 \quad$ b Faculty of Forestry, University of Toronto, 33 Willcocks Street, Toronto, ON, M5S 3B3,

7 Canada

8 c Forest Research and Monitoring Section, Ontario Ministry of Natural Resources and

9 Forestry, 1235 Queen Street East, Sault Ste. Marie, ON, P6A 2E5, Canada

10 Keywords: Airborne laser scanning (ALS), multi-seasonal imagery, Sentinel-2A, sensor fusion,

11 variable selection 


\section{Abstract}

Advanced forest resource inventory (FRI) information is of critical importance for optimizing

14 the forest value chain. Remote sensing offers a cost-effective option for estimating forest inventory

15 and biophysical variables over large areas. The objective of this study was to examine the utility

16 of multi-seasonal multispectral satellite imagery and airborne laser scanning (ALS) data for

17 estimating basal area, species mixture, and stem density for an uneven-aged tolerant hardwood

18 forest in Ontario, Canada. Using random forest (RF) regression as a diagnostic tool, three 19 multispectral sensors were examined: Landsat-5 TM, Sentinel-2A and WorldView-2. The 20 contribution of spectral predictors derived from different sensors as well as ALS height and 21 intensity metrics were evaluated using RF variable importance. As part of a two-step variable 22 selection framework, all the predictor variables were grouped into clusters using a hierarchical 23 variable clustering technique, which revealed the distinctiveness between information contained 24 in spectral predictors, height metrics, and intensity-based metrics. This indicates that ALS intensity 25 data carry unique information complementary to near-infrared bands of multispectral sensors for 26 forest characterization. Compared to single date images, multi-seasonal imagery proved to be more 27 accurate for modelling FRI variables, especially when combined with ALS data. Despite its limited 28 spatial resolution, Sentinel-2A was found to be the most cost-effective image source for enhancing 29 ALS-based inventory models. Using variables determined by the variable selection procedure, best 30 subsets regression outperformed the RF models developed during diagnostic analysis, resulting in 31 a suite of accurate and parsimonious predictive models, with coefficients of determination of 0.73 , 320.90 and 0.67 , for BA, conifer RBA and SD, respectively. 


\section{Introduction}

Forests are essential resources given that humans rely on them for social, economic, and environmental well-being (Hansen et al., 2013; Falkowski et al., 2009; Bonan, 2008). Over the past few decades, awareness of a changing climate, increasing energy prices, and enhanced concern for environmental issues have resulted in calls for more accurate, comprehensive and costeffective forest monitoring systems (Puddister et al., 2011; Wulder et al., 2004). Due to the labourintensive nature of ground-based forest mensuration, numerous efforts have been made to derive spatially explicit forest information using remote sensing. Considering the demand for sustainable forest management, information on forest structure and composition is of critical importance to informed silvicultural decisions and optimization of the forest value chain (Pitt \& Pineau, 2009).

Owing to its capability for providing a synoptic view of the earth's surface in a repetitive and economical manner, remote sensing has proven to be a useful technology for forest management (Giri et al., 2011; McRoberts et al., 2010). During the past few decades, research has focused on the extraction of forest biophysical and inventory variables (i.e., forest structural attributes) at various scales with optical remote sensing systems (Song, 2007; Hyyppä et al., 2000; Peterson et al., 1988). Despite the availability of numerous advanced image processing techniques with varying levels of reported success, optical remote sensing continues to lack the inherent capability of measuring the vertical structure of the forest (Mora et al., 2013; Ozdemir \& Karnieli, 2011; Falkowski et al., 2009), although the increasing availability of high spatial resolution imagery has alleviated this issue to some extent (Xu et al., 2015; Chen et al., 2012; Pasher \& King, 2010). However, predictive models based on optical data have yet to gain sufficient accuracy and precision to become operational (Xu et al., 2015). In contrast, airborne laser scanning (ALS) 
characterizes forest structure in the form of three-dimensional (3D) point clouds, thus containing unique information on the vertical characteristics of the forest (Lim et al., 2003).

Holmgren et al. (2008) compared high spatial resolution airborne multispectral camera data to discrete return ALS data for species classification in southern Sweden using an individual treebased approach; the overall accuracy of the multispectral data was found to be slightly lower than that of the ALS data (i.e., $88 \%$ and 91\% respectively). Erdody and Moskal (2010) estimated canopy height and canopy base height using ALS data and digital image data collected simultaneously. Even though the synergy of both data sources led to the highest accuracy for both canopy fuel attributes being modelled, the goodness-of-fit of the imagery-only model was approximately $50 \%$ of the ALS model. Similar results have been reported where multispectral imagery and ALS data were used to model stem volume as well as the volume and biomass of shrub vegetation (Tonolli et al., 2011; Estornell et al., 2012). Given the enhanced accuracy of the synergistic approach, there is a strong incentive for incorporating optical data into existing ALSbased forest inventories (Laurin et al, 2014; Koch, 2010; Dalponte et al., 2008). However, systematic analysis examining the utility of optical data with varying specifications has been scarce in the context of modelling FRI and biophysical variables over large areas. Given the higher acquisition costs of very high spatial resolution imagery compared to freely available datasets (e.g., Landsat TM and Sentinel-2A), the benefits of high spatial resolution data should be well understood relative to what can be achieved with imagery of moderate spatial resolution (i.e., 10 to $30 \mathrm{~m}$ ). In particular, multitemporal, moderate-resolution remote sensing data has exhibited strong potential for forest type classification, species differentiation and estimation of forest inventory variables (Chrysafis et al., 2017; Zhu \& Liu, 2014; Li et al., 2013). However, the utility 
77 of multitemporal optical remote sensing data compared to ALS data has not been examined to any

78 significant degree in the context of FRI.

Given the nature of multitemporal remote sensing and ALS data, a very large number of 80 predictor variables can be derived, many of which exhibit high levels of collinearity (Maltamo \& 81 Gobakken, 2014). Due to the lack of statistical assumptions on the predictor variables, non82 parametric techniques pose a popular solution to this dilemma (Penner et al., 2013; Breidenbach 83 et al., 2010; Hudak et al., 2008). Nonetheless, non-parametric models are generally less amenable 84 to interpretation, owing to relatively complex model structures. A recent study compared the 85 random forest (RF) regression technique with generalized linear models (GLMs) for modelling vascular plant species richness, and the latter was found to be more parsimonious and accurate 87 (Lopatin et al., 2016). A similar comparison was conducted by Penner et al. (2013) where RF was deemed more suitable for modelling FRI variables than parametric regressions because it does not 89 require model stratification to reach competitive accuracy. However, this study did not make use 90 of a systematic variable selection procedure in the comparison. As a result, the regression models 91 might not have reached optimal accuracy, due to their higher levels of reliance on selected 92 variables (Mutanga et al., 2012; Cohen et al., 2003).

As ALS has matured, more efforts have been made to derive metrics based on intensity data, 94 rather than height data alone (Shang et al., 2017; García et al., 2010; Donoghue et al., 2007). These 95 studies have demonstrated that predictive models taking advantage of ALS height and intensity 96 metrics were more accurate than those based on height data alone. With the advent of multispectral 97 ALS sensors (e.g., Teledyne Optech Titan), height and intensity data are being collected at multiple wavelengths. A recent study utilized Titan multispectral ALS data for species classification at the 99 individual tree level, and the intensity data were found to contribute information complementary 
to 3D metrics (Budei et al., 2017). Regarding the acquisition mechanism, ALS intensity data are distinctive from the near-infrared (NIR) channels of multispectral sensors. However, the similarities and differences between these two types of "spectral" data are not well understood, especially considering the difficulties in calibrating ALS intensity data (Korpela et al., 2010).

Given this context, the overall aim of this study is to evaluate the potential of multispectral imagery for enhancing ALS-based estimation of basal area, species mixture, and stem density in an uneven-aged tolerant hardwood forest in the Great Lakes-St. Lawrence Forest Region, Ontario, Canada. The specific objectives are: (i) to examine the utility of multi-seasonal imagery for estimating selected forest inventory variables compared to single-date imagery; (ii) to assess the cost-effectiveness of high spatial resolution data (i.e., WorldView-2) relative to freely available multispectral data (i.e., Landsat-5 TM and Sentinel-2A); (iii) to compare and contrast the information contained in the near-infrared bands of these sensors to ALS intensity data; and (iv) to examine the accuracy of RF relative to linear regression based on variables carefully selected with a two-step variable selection strategy.

\section{Material and methods}

\subsection{Study Area}

The Haliburton Forest (HF) $\left(45^{\circ} 17^{\prime} \mathrm{N}, 78^{\circ} 34^{\prime} \mathrm{W}\right)$ is located within the Great Lakes - St. Lawrence (GLSL) Forest Region of Ontario, Canada (Figure 1). The average annual temperature and precipitation is approximately $4.9^{\circ} \mathrm{C}$ and $1100 \mathrm{~mm}$ respectively (Sackett et al., 2012). HF is an actively managed, privately owned forest covering 23,800 ha with 80 percent forest cover (Figure 1). Sugar Maple (Acer saccharum) is the dominant tree species, with Balsam Fir (Abies balsamea), eastern hemlock (Tsuga canadensis), American Beech (Fagus grandifolia), and yellow birch (Betula alleghaniensis) being co-dominant species (Hossain \& Caspersen, 2012). The 
123 implementation of partial harvest silviculture systems for the past 40 years resulted in an uneven-

124 aged landscape in the HF (Arii et al., 2008; Mrosek et al., 2006).

125

126

127

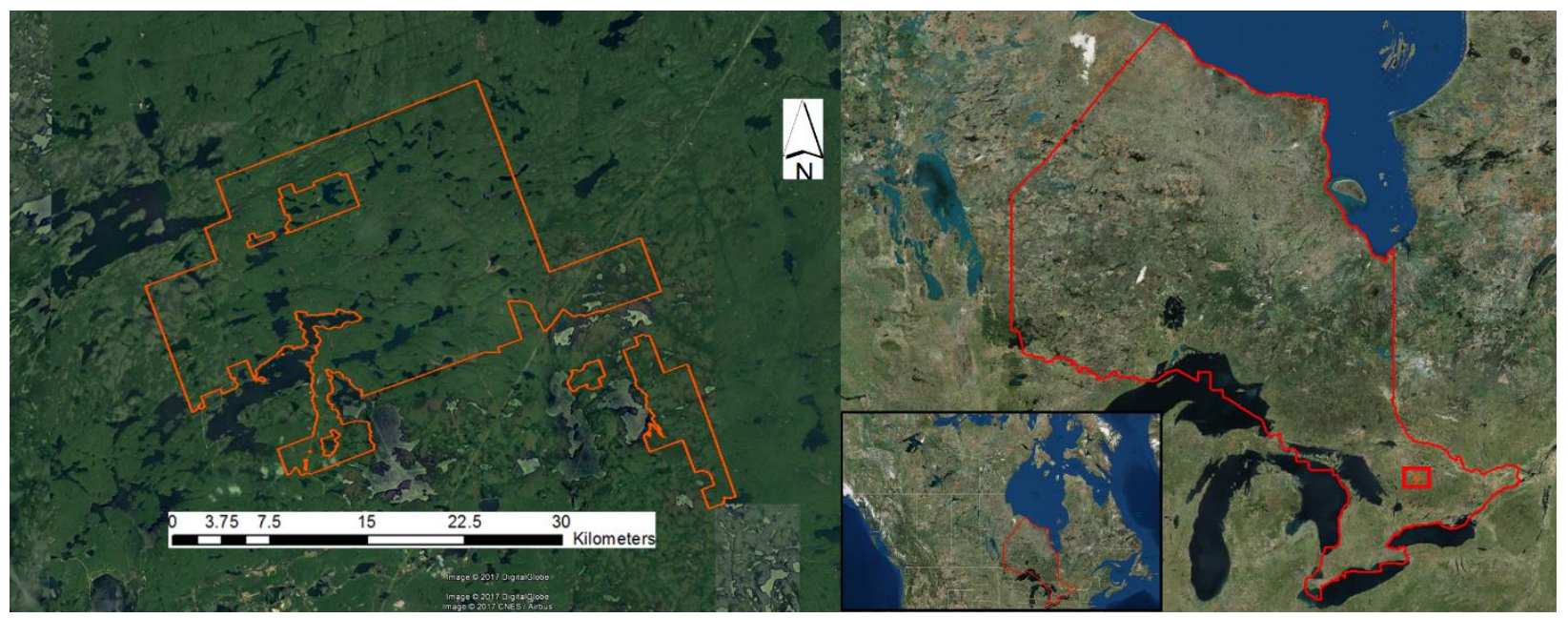

Figure 1 Location of the study area in Ontario, Canada (Source: Google Maps, 2017).

\subsection{Field data}

During the summers of 2010 and 2011, 97 sampling plots were established in the HF following a stratified random sampling strategy, covering a gradient of ecosite and canopy openness conditions. All plots were circular, with a radius of $28.2 \mathrm{~m}$ (i.e., $0.25 \mathrm{ha}$ ). For all trees with a $\mathrm{DBH} \geq 8 \mathrm{~cm}$ in each plot, $\mathrm{DBH}$, tree species, and status (living or dead) were collected. The plot center locations were georeferenced with a Trimble ProXT GPS unit to achieve sub-meter accuracy. A suite of forest inventory variables was derived from the field data, including plot-level basal area (BA), stem density (SD), and the proportion of conifer trees by relative basal area (RBA) as a surrogate for species mixture, such that forest structural and species information is available for decision support in forest management. Summary statistics of these forest inventory variables are provided in Table 1. 
Table 1 Descriptive statistics of the forest attributes for Haliburton Forest.

\begin{tabular}{ccccc}
\hline Attribute & Average & Min & Max & Standard deviation \\
\hline BA (m²/ha) & 28.31 & 9.75 & 45.88 & 7.39 \\
Conifer RBA (\%) & 0.31 & 0.00 & 0.94 & 0.24 \\
Stem density (Stems/ha) & 790.40 & 400.00 & 1784.00 & 334.20 \\
\hline
\end{tabular}

\subsection{ALS data}

Small-footprint discrete return ALS data (39 flight lines) were collected in 2009 with an ALTM 3100 sensor (Teledyne Optech Inc., Vaughan, Ontario, Canada) mounted in a Cessna Turbo 206 Stationair aircraft (Lim Geomatics Inc., Ottawa, Canada). The instrument was flown at an altitude of approximately $1500 \mathrm{~m}$ above ground level, with a scan half angle of $16^{\circ}$, a pulse repetition frequency of $70 \mathrm{kHz}$, a scan frequency of $36 \mathrm{~Hz}$, and $30 \%$ overlap between adjacent flight lines. This resulted in a nominal point density of 1.7 points $\mathrm{m}^{-2}$. A triangular irregular network (TIN) was created by the vendor based on ALS points classified as ground returns, which was used to normalize the ALS height data.

\subsection{Multispectral imagery}

The optical dataset used for this study consisted of 6 cloud-free, multi-seasonal images, acquired by three multispectral sensors (i.e., Landsat-5 TM, Sentinel-2A, and WorldView-2). Landsat-5 TM and WorldView-2 were selected due to their distinct spatial and spectral resolutions suitable for natural resources monitoring at different spatial scales. In contrast, Sentinel-2A covers the same spectral channels as Landsat-5 TM, yet provides enhanced spectral and spatial resolution, giving rise to its potential for forest applications. To examine the utility of multi-seasonal multispectral images for estimating FRI variables, two images were acquired for each sensor during leaf-on and leaf-off conditions (Table 2). The Landsat-5 TM scenes were atmospherically corrected using the Landsat Ecosystem Disturbance Adaptive Processing System (LEDAPS) 
158 (Masek et al., 2006). The Sentinel-2 SEN2COR processor implemented in the Sentinel Application 159 Platform (SNAP) (version 5.0.7) was used to convert top of atmosphere to surface reflectance for 160 the Sentinel-2A images (Vuolo et al., 2016). Atmospheric correction for the WorldView-2 images 161 was performed using the FLAASH atmospheric correction module in ENVI 5.4.

162 Table 2 Multi-seasonal multispectral imagery examined in this study.

\begin{tabular}{ccccc}
\hline Sensor & Resolution $(\mathbf{m})$ & $\begin{array}{c}\text { Leaf-on } \\
\text { acquisition }\end{array}$ & $\begin{array}{c}\text { Leaf-off } \\
\text { acquisition }\end{array}$ & Channels used \\
\hline Sentinel-2A & $10 \& 20$ & $2016-08-15$ & $2017-03-23$ & $2 \sim 8 ; 8 \mathrm{a} ; 11 ; 12$ \\
WorldView-2 & 2 & $2015-07-11$ & $2015-11-17$ & $1 \sim 8$ \\
Landsat TM & 30 & $2011-07-03$ & $2011-04-30$ & $1 \sim 5 ; 7$ \\
\hline
\end{tabular}

\subsection{Predictor variables}

In order to compare the utility of ALS- and imagery-based predictors for estimating FRI variables, we examined two groups of predictor variables from the remotely-sensed data: (1) height- and intensity-based metrics (Woods et al., 2011; Shang et al., 2017); and (2) spectral variables of different spectral and spatial resolutions corresponding to the specifications of Landsat-5 TM, Sentinel-2A, and WorldView-2 imagery (Table 2). Similar to the ALS metrics, where metrics were derived from returns intersecting each 0.25 ha plot, the spectral variables were obtained from pixels intersecting the individual plots. In addition to the plot-level average reflectance values for each band from the three sensors, the coefficient of variation (CV) was calculated as an image texture measure to test for the benefits of high spatial resolution imagery (St-Louis et al., 2009; Culbert et al., 2009; Kuplich et al., 2005). A total of 200 predictor variables were derived (104 ALS metrics and 96 spectral variables). Further, the inclusion of predictor variables from both data sources allows for a direct comparison between ALS intensity-based 
metrics and near-infrared data from multispectral instruments with different spectral and spatial resolutions for modelling FRI variables.

\subsection{Statistical analysis}

To determine the utility of optical imagery and ALS data for modelling FRI variables, a twostep modelling approach was developed (Figure 2). The first step aims to obtain an approximate estimation of the potential of optical imagery for assisting ALS-based predictive models of different forest attributes. In particular, predictor variables derived from the two data sources (ALS and optical imagery) were configured into four categories based on richness of data: leaf-on imagery only, leaf-off imagery only, leaf-on + leaf-off imagery, and leaf-on + leaf-off imagery + ALS. Since we incorporated Landsat-5 TM, Sentinel-2A, and WorldView-2 imagery into our analyses, spectral predictor variables derived from these sensors were examined independently from each other. As a result, we obtained a total of 12 predictor groups (four richness categories $x$ three sensors).

As a non-parametric technique gaining popularity in the remote sensing community (Belgiu \& Drăguţ, 2016; Rodriguez-Galiano et al., 2012; Pal, 2005), the RF model is free from assumptions based on data distribution (Breiman, 2001). This feature of RF makes it a suitable tool for diagnostic analysis and establishing goodness-of-fit benchmarks using different groups of predictor variables (i.e., without the need to adjust for collinearity between large groups of predictor variables). After RF was performed on each of the 12 predictor groups for the three selected forest attributes, $\mathrm{R}^{2}$ values derived from out-of-bag (OOB) data were used as surrogates for goodness-of-fit, since they are generally reported as conservative estimates of model accuracy (Oliveira et al., 2012). For comparison purposes, full RF models utilizing all the 200 predictor variables were developed for each forest inventory variable. Being an ensemble tree-based model, 
RF consists of a number of decision tree classifiers, and each tree classifier is trained with a subset of input features using a bootstrap sample of the original calibration data. This allows for the derivation of variable importance measures using OOB data. To determine the predictor variables most sensitive to each forest inventory variable, variable importance scores were obtained from the three full models. Owing to its explicit connection to model accuracy, the average percentage decrease in mean squared error (\%IncMSE) was used to represent variable importance.

The R package randomForest (Liaw \& Wiener, 2002) was used to calibrate the RF models. Since these models primarily serve the purpose of internal comparisons at the diagnostic stage (i.e., between different predictor groups for different forest attributes), parameter tuning was not conducted. The default parameters were adopted, with the number of regression trees (i.e., ntree) set to 500, the number of predictor variables sampled at each split (i.e., mtry) set to one third of the total number of variables, and a minimum terminal node size (i.e., nodesize) of five. Despite

211 its ease of use and reasonably good predictive power, RF can be difficult to interpret and more 212 computationally demanding compared to regression models. Therefore, we aim to develop more 213 parsimonious and potentially more accurate models in the second step of our modelling framework. 214 After the goodness-of-fit baselines were established for all 12 predictor groups in the first step, those exhibiting good predictive potential were further analyzed in the second step (i.e., variable 216 reduction and final model development) (Figure 2).

217 Due to the large number of predictor variables with within each predictor group, a two-step 218 variable selection strategy was developed to facilitate the development of parsimonious and 219 interpretable models. The primary objectives of common variable selection approaches are to 220 remove predictors with low relevance to the variables of interest (i.e., confounding variables) and 221 reduce the redundancy between remaining variables (Zhu et al., 2015; Galelli \& Castelletti, 2013; 
222 Chen et al., 2012). We first reduced redundancy within the initial set of predictor variables using

223 a hierarchical variable clustering algorithm (hclustvar) implemented in the R package ClustOfVar

224 (Chavent et al., 2011). This clustering process can be conceptualized and visualized through a

225 dendrogram: using a bottom-up approach, the most correlated predictors identified by the squared

226 Pearson correlation are merged at each step until one cluster remains. To determine the optimal

227 number of variable clusters to retain after partitioning the dendrogram, the adjusted Rand index

228 (Hubert \& Arabie, 1985) was calculated. As a result, highly correlated predictor variables were

229 grouped into the same clusters, while relatively independent variables remained in different

230 clusters. Subsequently, synthetic variables equivalent to the first principle component of a PCA

231 applied to the variables in the individual clusters were created to represent these variable clusters,

232 thus eliminating redundant predictor variables. The second step of our variable selection strategy

233 selected variables relevant to the forest attributes of interest. The synthetic variables emerging

234 from the variable clustering phase were evaluated using the variable importance measure

235 (\%IncMSE) of RF. To improve the computational efficiency of our model (i.e., directly related to

236 the number of variables in a model) and alleviate the risk of developing a model with high variance,

237 the top 30 synthetic variables with the highest variable importance scores were selected. To make

238 the final models interpretable and easy to apply over large areas, predictor variables with the

239 highest loadings on each of the 30 synthetic variables were used in subsequent analyses. Since the

240 first step of our variable selection strategy only examines the similarity between predictor variables,

241 the reduction of redundancy is independent from the choice of response variables. Therefore,

242 variable clustering based on the initial 200 predictor variables was performed only once. In contrast,

243 the second step was undertaken three times, one for each forest attribute, assuming the varying

244 utilities of the predictor variables for different forest attributes. 
After both phases of variable selection, the total number of predictor variables were 246 effectively reduced from 200 to 34 for all the response variables (Table 3). Since these carefully 247 selected predictor variables have low redundancy and high relevancy to the response variables, 248 multiple linear regression models with a significance level of 0.05 were developed using the best 249 subsets technique (Hudak et al., 2006). The Bayesian information criteria (BIC) was used to select 250 the best model for each response variable. To avoid overfitting, the maximum number of predictor 251 variables in each regression model was set to six, even if the lowest BIC value corresponded to a 252 more complex model. During model selection, the variance inflation factors (VIFs) were closely 253 monitored, and regression models suffering from high-collinearity (i.e., containing variables with 254 VIFs of over 10) were discarded. To examine whether the assumptions of linear regression were 255 met by the candidate models, statistical tests were performed using the Shapiro-Wilk Test and the 256 Breusch-Pagon Test for normality of residuals and homoscedasticity respectively (Royston, 1982; 257 Breusch \& Pagon, 1979). To assess the robustness of predictive models over a full range of forest 258 conditions, calibration and validation of the regression models was conducted using a 10-fold 259 cross-validation approach, where predictive accuracy was measured by coefficient of 260 determination $\left(\mathrm{R}^{2}\right)$ and relative root mean square error (rRMSE). 


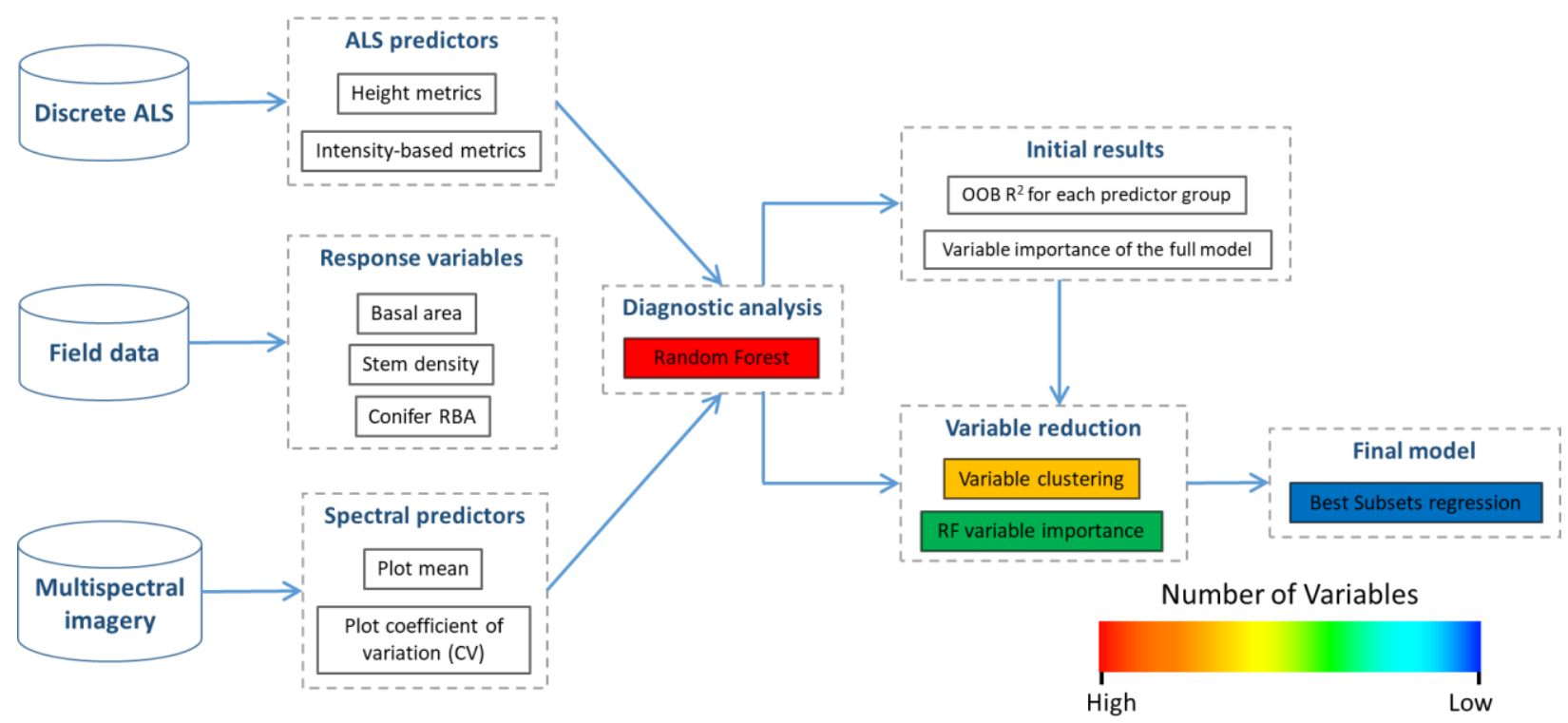

262 Figure 2 Workflow diagram of the two-step modelling framework consisting of: (i) diagnostic

263 analysis to determine the predictive potential of different predictor groups and the most influential

264 predictor variables for each forest inventory variables using RF; and (ii) final model development

265 stage where accurate and parsimonious regression models are constructed following a two-step

266 variable selection strategy. 
Table 3 Predictor variables selected by the best subsets approach for each forest inventory variable.

\begin{tabular}{|c|c|c|c|c|}
\hline Variables & Variable description & $\mathbf{B A}$ & $\begin{array}{l}\text { Conifer } \\
\text { RBA }\end{array}$ & $\begin{array}{c}\text { Stem } \\
\text { Density }\end{array}$ \\
\hline D1 & $1^{\text {st }}$ density metric (Woods et al., 2008) & $\sqrt{ }$ & $\sqrt{ }$ & \\
\hline D2 & $2^{\text {nd }}$ density metric & & & $\sqrt{ }$ \\
\hline D3 & $3^{\text {rd }}$ density metric & $\sqrt{ }$ & & \\
\hline D8 & $8^{\text {th }}$ density metric & $\sqrt{ }$ & & \\
\hline Elev.MAD.median & $\begin{array}{l}\text { Median of the absolute deviations from } \\
\text { the overall median }\end{array}$ & & & $\sqrt{ }$ \\
\hline Elev.P75 & $75^{\text {th }}$ height percentile & & & $\sqrt{ }$ \\
\hline Elev.P95 & $95^{\text {th }}$ height percentile & $\sqrt{ }$ & & \\
\hline Int.kurtosis & Intensity kurtosis & & & $\sqrt{ }$ \\
\hline Int.mean & Intensity mean & & $\sqrt{ }$ & \\
\hline Int.P25 & $25^{\text {th }}$ height percentile & & & $\sqrt{ }$ \\
\hline Int.P80 & $80^{\text {th }}$ height percentile & $\sqrt{ }$ & & \\
\hline Int.P90 & $90^{\text {th }}$ height percentile & & & $\sqrt{ }$ \\
\hline Int.P99 & $99^{\text {th }}$ height percentile & & & $\sqrt{ }$ \\
\hline Int.stddev & Intensity standard deviation & & & $\sqrt{ }$ \\
\hline $\begin{array}{l}\text { Percentage.all.returns. } \\
\text { above.mean }\end{array}$ & $\begin{array}{l}\text { Percentage of all returns above the mean } \\
\text { height }\end{array}$ & & & $\sqrt{ }$ \\
\hline $\begin{array}{l}\text { Percentage.first.returns. } \\
\text { above. } 2\end{array}$ & Proportion of first returns above $2 \mathrm{~m}$ & $\sqrt{ }$ & $\sqrt{ }$ & \\
\hline S2A_Aug_B3_cv & Sentinel-2A Leaf on green cv & & & $\sqrt{ }$ \\
\hline S2A_Aug_B7_mean & Sentinel-2A Leaf on red edge 3 mean & $\sqrt{ }$ & $\sqrt{ }$ & \\
\hline S2A_Mar_B11_mean & Sentinel-2A Leaf off SWIR 1 mean & $\sqrt{ }$ & $\sqrt{ }$ & \\
\hline S2A_Mar_B12_mean & Sentinel-2A Leaf off SWIR 2 mean & $\sqrt{ }$ & $\sqrt{ }$ & \\
\hline S2A_Mar_B2_cv & Sentinel-2A Leaf off blue cv & $\sqrt{ }$ & & \\
\hline S2A_Mar_B7_mean & Sentinel-2A Leaf off red edge 3 mean & & $\sqrt{ }$ & \\
\hline Wv_Jul_B2_mean & WorldView-2 Leaf on blue mean & & & $\sqrt{ }$ \\
\hline Wv_Jul_B3_mean & WorldView-2 Leaf on green mean & & & $\sqrt{ }$ \\
\hline Wv_Jul_B5_mean & WorldView-2 Leaf on red mean & & & $\sqrt{ }$ \\
\hline Wv_Jul_B6_cv & WorldView-2 Leaf on red edge cv & & $\sqrt{ }$ & $\sqrt{ }$ \\
\hline Wv_Jul_B8_mean & WorldView-2 Leaf on NIR2 mean & $\sqrt{ }$ & $\sqrt{ }$ & $\sqrt{ }$ \\
\hline Wv_Nov_B1_cv & WorldView-2 Leaf off coastal cv & & & $\sqrt{ }$ \\
\hline Wv_Nov_B1_mean & WorldView-2 Leaf off coastal mean & & & $\sqrt{ }$ \\
\hline Wv_Nov_B5_mean & WorldView-2 Leaf off red mean & $\sqrt{ }$ & & \\
\hline Wv_Nov_B6_mean & WorldView-2 Leaf off red edge mean & $\sqrt{ }$ & $\sqrt{ }$ & \\
\hline Wv_Nov_B8_cv & WorldView-2 Leaf off NIR2 cv & & $\sqrt{ }$ & $\sqrt{ }$ \\
\hline Lt5_Apr_B3_mean & Landsat-5 TM leaf off red mean & $\sqrt{ }$ & & \\
\hline Lt5_Apr_B4_mean & Landsat-5 TM leaf off NIR mean & $\sqrt{ }$ & & \\
\hline
\end{tabular}




\section{Results and discussion}

270

271

272

273

274

275

276

277

278

279

280

281

282

283

284

285

286

287

288

289

290

291

\subsection{Diagnostic analysis using RF}

Single-season spectral predictors exhibited varying predictive power for each of the three forest inventory variables (Figure 3). For BA and conifer RBA, spectral predictors derived from Landsat-5 TM and Sentinel-2A under leaf-off conditions exhibited greater accuracy than those from leaf-on. The leaf-on WorldView-2 image proved to be more useful than the leaf-off acquisition for modelling BA, but the trend is reversed for species mixture (i.e., conifer RBA). This can be attributed to the distinctive spectral signatures for deciduous and conifer trees under leaf-off conditions, when deciduous trees are devoid of foliage. In the context of area-based approach (ABA), the enhanced spectral differences between conifer and deciduous species under leaf-off conditions contributes directly to the estimation of the percentage of conifer trees in each plot. For stem density, similar accuracies were achieved by the leaf-on and leaf-off spectral predictors, with the predictive power of the latter lagging slightly behind. However, when these two groups of predictors were combined, their synergistic predictive power exhibited greater correspondence with stem density (Figure 3). In contrast, the accuracy of the RF models based on multi-seasonal imagery was not significantly improved from the best single season models for BA and conifer RBA. This holds true for all three sensors, with the only exception being the WorldView-2 model for conifer RBA, where the multi-seasonal model outperformed the single season models.

Among the spectral models, Landsat-5 TM exhibited the poorest overall utility for modelling the selected forest inventory variables, due to its relatively coarse spatial and spectral resolution. Spectral predictors derived from Sentinel-2A featured the highest accuracy for modelling BA. Nonetheless, WorldView-2 was found to be the most successful optical sensor for conifer RBA 
292 and stem density. After ALS-based predictors were added to the spectral models, the predictive

293 power of the RF models was greatly improved for BA and stem density. In conjunction with the

294 relatively poor accuracy of the spectral models for these two inventory variables (i.e., $\mathrm{R}^{2}<0.5$

295 regardless of sensor), this indicates the unparalleled utility of ALS data for modelling forest

296 structural characteristics compared to optical sensors. Interestingly, despite the varying predictive

297 power of the spectral models for stem density, their accuracies converged after ALS metrics were

298 added, implying that optical sensors do not contribute complementary information.

When it comes to species mixture, the addition of ALS-based predictors only led to marginal

300

301

302

303

304

305

306

307

308

309

310

311

312

313

improvement in model accuracy for Landsat-5 TM and Sentinel-2A. For WorldView-2, the combined model (i.e., WorldView-2 + ALS) was outperformed by the multi-seasonal WorldView2 model. The reason behind this is likely twofold. First, even though RF does not assume predictor variables to be statistically independent, the large number of highly correlated ALS metrics can hinder model performance, thus requiring a variable selection approach to reach optimum accuracy (Chrysafis et al., 2017; Immitzer et al., 2017; Liu et al., 2017; Chan \& Paelinckx, 2008). Second, ALS data carry limited information on species, especially at the plot level (White et al., 2016; Breidenbach et al., 2010; Brandtberg, 2007). With the large number of ALS metrics (i.e., 104) added to the multi-seasonal WorldView-2 model (i.e., containing 32 spectral variables), the overall probability of obtaining a useful variable for modelling species mixture is decreased at each split, given the parameter 'mtry' is set to one third of the total number of variables, resulting in reduced performance. Similarly, the full BA model did not outperform the more parsimonious model based on multi-seasonal Sentinel-2A predictors and ALS metrics. For the other two inventory variables, the best subsets models reached comparable accuracy as the corresponding full models, indicating 
314 that the combination of only one optical sensor and ALS is sufficient for enhancing ALS-based 315 FRIs.

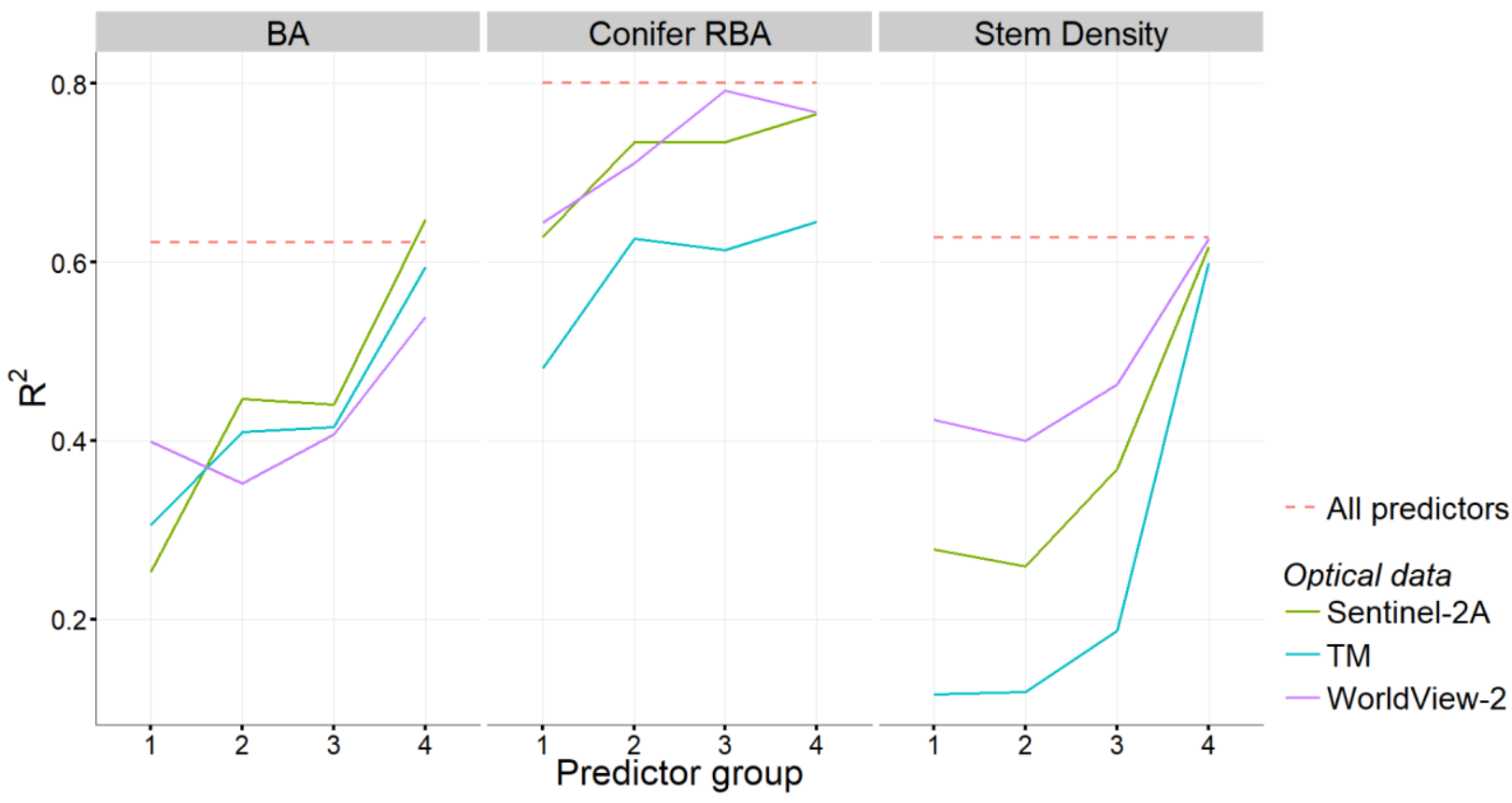

316

317

318

319

320

321

322

323

324

325

326

327

328

Figure 3 Predictive accuracies for three forest inventory variables derived from RF OOB data, based on four data richness groups for three optical sensors. Group 1: leaf-on imagery only; Group 2: leaf-off imagery only, Group 3: leaf-on + leaf-off imagery; Group 4: leaf-on + leaf-off imagery + ALS. The accuracies of the full models were also added to the graph as a reference. Because these full models make use of all the available spectral and ALS predictors, dashed lines were used to represent the accuracy of the full models for illustrative purposes.

The variable importance information obtained from the three full models corresponded well with the predictive power exhibited by the different predictor groups shown in Figure 3. For BA, the top 30 most important variables were represented by two general classes of predictor variables. The first class mostly consists of spectral predictors derived from Landsat-5 TM and Sentinel-2A images acquired under leaf-off conditions (Figure 4). This corroborates the stronger predictive power of the multi-seasonal and leaf-off models based on these two sensors compared to those 
based on WorldView-2 (Figure 3). Considering the superior spatial and spectral resolution of WorldView-2 relative to that of Landsat-5 TM, it is likely that the SWIR bands available on Sentinel-2A and Landsat-5 TM contribute to the improved predictive power of these two sensors over WorldView-2. For instance, the SWIR band of the leaf-off Landsat-5 TM image ranked the fourth for modelling BA (Figure 4). In addition, the leaf-off WorldView-2 image was acquired in November, while the leaf-off Sentinel-2A and Landsat-5 images were acquired in March and April 335 respectively. Even though all three months represent leaf-off conditions, the lack of model performance associated with the November WorldView-2 image could in part be attributed to the remnant foliage on deciduous trees in November. This may have a negative impact on the relationship between woody materials and multispectral bands of the leaf-off WorldView-2 image, especially in the visible range of the spectrum, considering the most important variables for BA are visible bands from Sentinel-2A and Landsat-5 TM. The second class of predictors that 341 exhibited potent utility for modelling BA is comprised of height percentiles, density metrics, and 342 other ALS metrics that characterize the statistical distribution of ALS height data, which 343 corroborates well with the findings of previous studies which show that ... stands with higher BA 344 have bigger trees that are taller (Penner et al., 2013; Packalén \& Maltamo, 2007; Gobakken \& 345 Næsset, 2004).

Similar to BA, spectral predictors derived from leaf-off images exhibited the strongest 347 predictive power towards conifer RBA (Figure 4). Leaf-on spectral predictors were also found to 348 carry important information on species mixture, albeit with slightly lower rankings. Considering 349 the distinctive spectral signature between deciduous and conifer trees under leaf-off conditions, 350 this is not surprising. Furthermore, local spectral heterogeneity (i.e., measured by band CVs) was 351 found to be an influential predictor for conifer RBA. Unlike the case with the BA model, where 
352 the most influential spectral predictors represented visible wavelengths, the top predictors for

353 conifer RBA included spectral predictors covering the full range of spectrum (i.e., visible, red edge,

354 NIR, and SWIR). In addition to the significant potential of spectral predictors for modelling

355 species mixture, the domination of one class (i.e., variable cluster 2) of predictors indicates one

356 drawback of the RF algorithm that impacts its variable importance rankings as well as its

357 performance. As can be seen from the top-ranked variables for conifer RBA, several spectral 358 predictors from the same sensor with similar wavelengths were included (e.g., the red edge, NIR1, 359 and NIR2 bands of the leaf-off Worldview-2 image; the red, green, and blue bands of the leaf-off 360 Sentinel-2A image). Upon examining the correlation between these variables, they were found to 361 be highly correlated, with Pearson correlation coefficients greater than 0.9 in both cases. Given 362 that these variables carry almost identical information, it is highly likely that they were used 363 interchangeably, to a large extent, at different splits in the individual regression trees within the 364 RF model. As a result, their variable importance scores are skewed because they are shared 365 between these highly correlated predictor variables. In addition, a variable importance graph 366 inundated with important yet highly correlated variables hinders the interpretation of the 367 contribution of weaker predictors that carry complementary information on the response variable. 368 For instance, the contribution of ALS metrics for modelling species mixture cannot be well 369 understood with only two ALS metrics present in the list of top 30 variables. The presence of 370 highly correlated variables in RF also inflates the probability of these variables being selected at 371 different splits, thus increasing the correlation between individual regression trees. This will 372 increase the variance of the RF model, compromising its predictive performance. Therefore, the 373 use of a variable selection technique in conjunction with RF is highly recommended for not only 
374 predictive purposes, but also interpretation of variable importance (Karlson et al., 2015; Naidoo et 375 al., 2012; Nicodemus et al., 2010).

In comparison to BA and conifer RBA, the RF model for stem density benefited from a wider 377 range of predictor variables, encompassing variables from four out of seven variable clusters 378 (Figure 4). In contrast to the two previous forest attributes, where spectral predictors were the most 379 influential variables, the predictive power of the stem density model can be mostly attributed to 380 ALS metrics, with metrics that characterize the variability of the ALS height and intensity data 381 (e.g., Elev.variance, Elev.stddev, Int.AAD, Int.variance) being the most important predictors. The 382 importance of these metrics for modelling stem density and size class distribution has been 383 described in Shang et al. (2017). In addition to ALS-based predictors, several spectral variables 384 exhibited respectable predictive power towards stem density. In particular, the blue band from the 385 leaf-on WorldView-2 image (i.e., Wv_Jul_B2_mean) ranked fifth in the list of top 30 most 386 important variables. A study conducted by Ozdemir \& Karnieli (2011) examined the utility of a 387 spring (i.e., May) WorldView-2 image for modelling forest inventory variables for afforestation 388 and the blue band was identified as the most useful channel for BA, stem volume, and stem 389 diameter diversity. In our RF model, due to the presence of highly correlated variables at the top 390 of the list, the contribution of these spectral variables towards stem density modelling is biased, 391 and likely underrepresented in this instance. 


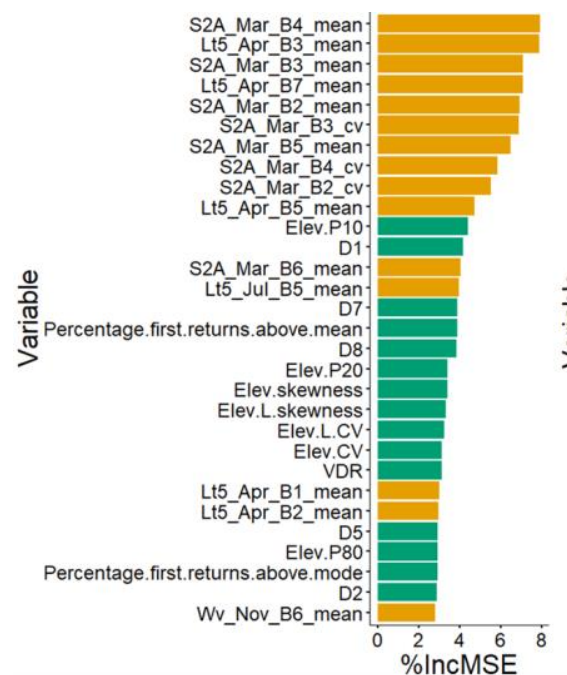

(a)

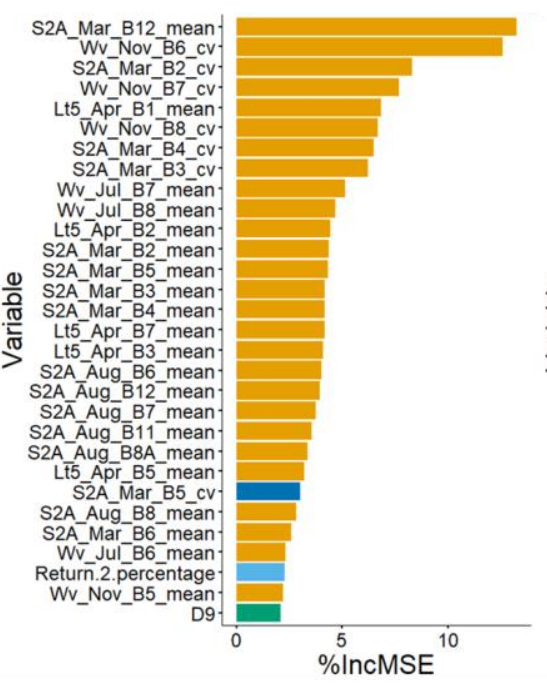

(b)

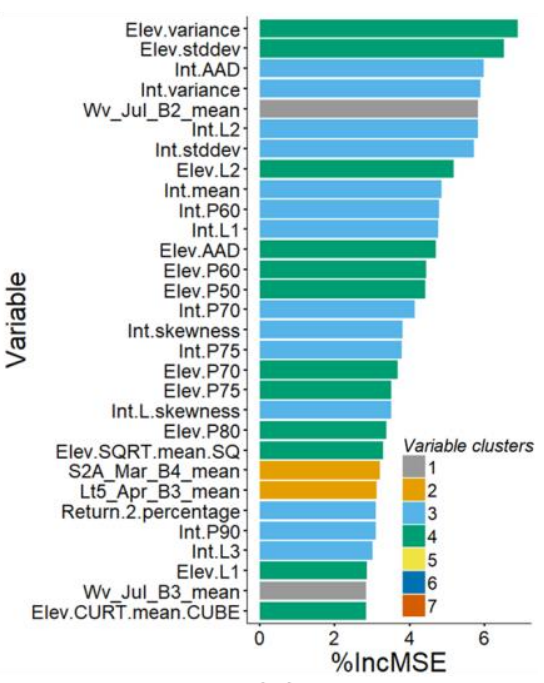

(c)
392

393

394

395

396

397

398

399

400

401

402

403

404

405

406

407

Figure 4 Variable importance scores for the top 30 variables emerging from the full RF models developed using RF with all the 200 predictor variables for each forest inventory variable: (a) BA, (b) Conifer RBA, (c) Stem density. For interpretation purposes, the dendrogram encompassing all 200 variables is partitioned to represent seven clusters, and the variables falling into each cluster are color coded accordingly. The first cluster is represented by a subset of leaf-on WorldView-2 spectral variables, the second by multi-seasonal spectral variables from all three sensors, the third by return proportions and the majority of ALS intensity metrics, the fourth by a variety of ALS height metrics, the fifth by Landsat-based texture variables, the sixth by a subset of texture metrics derived from Sentinel-2A, and the seventh by a subset of intensity metrics.

\subsection{Variable selection}

Considering the large number of predictor variables (i.e., 200) processed with the variable clustering algorithm, visualization of the corresponding dendrogram can be challenging. To showcase the concept and reveal the relationship between ALS metrics and spectral predictors derived from the three optical sensors, hierarchical clustering was performed on the 34 remaining predictor variables after variable selection (Figure 5). At the bottom of the dendrogram (area to 
408 the left in Figure 5), the most similar variables are grouped into the same clusters, including 409 spectral bands covering similar ranges of the spectrum and adjacent height and intensity percentiles. 410 However, the correlation among these variables have already been greatly reduced compared to 411 the full dendrogram containing all 200 variables. For example, the standard deviation and variance 412 of the intensity data are not simultaneously present in Figure 5 due to the application of the variable 413 selection procedures. Similarly, only the mean reflectance of the leaf-on WorldView-2 NIR2 band 414 remains after variable selection, while the counterparts for the red edge and NIR1 bands have been 415 discarded, due to the high correlation between these channels. When this dendrogram containing 41634 variables is cut to represent three functional clusters, the first one is represented by multi417 seasonal spectral predictors, the second by ALS intensity-based metrics, and the third by height 418 metrics with a mixture of two spectral predictors from WorldView-2 imagery and one intensity419 based metric. This indicates that spectral predictors and structural metrics derived from ALS height 420 and intensity data carry distinctive information for modelling forest inventory variables, even 421 though the ALS instrument operates at the near-infrared wavelength. This could be attributed to 422 the nature of the ALS height and intensity data as three-dimensional measurements of the forest. 423 The intensity values associated with individual ALS returns can be considered indicators of the 424 strength (or power return) of the backscattered energy (Wehr \& Lohr, 1999), which is conceptually 425 comparable to uncalibrated DN values from multispectral sensors. However, the spectral 426 measurements obtained by multispectral sensors are primarily influenced by optical properties of 427 the top of the canopy (Schlemmer et al., 2013; Meroni et al., 2004; Goward \& Huemmrich, 1992). 428 Even with multiple scattering between canopy layers considered, information contained in 429 multispectral data cannot effectively characterize the vertical distribution of the forest canopy. On 430 the contrary, ALS intensity data are collected at various heights within a forest as the laser pulse 
431 travels through the canopy, thus containing information more relevant to the vertical structure of

432 the forest. For example, the variability of intensity values has been associated with overall canopy

433 density, which facilitated the estimation of stem density for small diameter trees (Shang et al.,

434 2017). Using an individual tree-based approach, Holmgren and Persson (2004) found the standard

435 deviation of ALS intensity data of critical importance to the differentiation between spruce and

436 pine. At the plot scale, intensity percentile metrics also exhibited strong potential for estimating

437 species mixture in plantation forests (Donoghue et al., 2007).

438

439

440

441

442

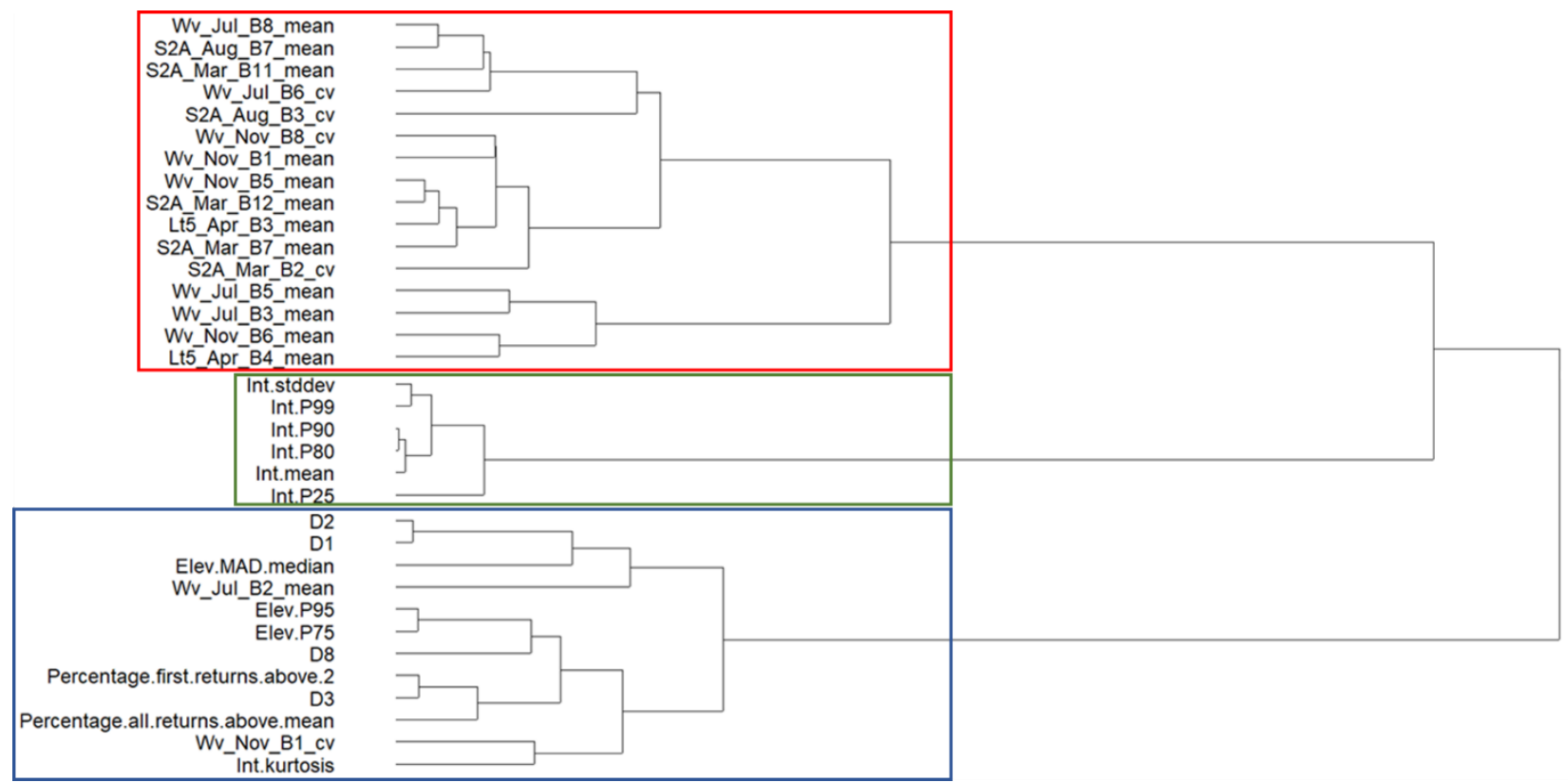

Figure 5 Variable dendrogram obtained by performing variable clustering on the 34 predictor variables selected by the best subsets approach. To reveal the structure of information contained in these variables, this dendrogram is partitioned to represent three variable clusters (highlighted by the colored boxes).

\subsection{Predictive performance of the regression models}

Compared to the RF models developed in the diagnostic analysis (Figure 3), the linear regression models exhibited consistent improvement in predictive accuracy. As can be seen from 
446 Table 4, the values of the three hybrid BA models all have $\mathrm{R}^{2}>0.7$, while the full RF model had $447 \mathrm{a} \mathrm{R}^{2}=0.62$. Similarly, the $\mathrm{R}^{2}$ of the linear conifer RBA models all exceeded 0.8 (i.e., $\geq 0.85$ in 448 three out of four cases), significantly higher than the accuracy of the full RF models (i.e., $R^{2}=0.8$ ). 449 The improvement in predictive accuracy can be attributed to the parsimonious structure of the 450 linear models, which was made possible by the removal of redundant and confounding variables 451 at the variable selection phase. In addition, the presence of strong linear predictors made significant 452 contributions towards enhancing model performance (e.g., multi-seasonal spectral variables for 453 BA and conifer RBA). In comparison, the linear models for stem density only slightly 454 outperformed the corresponding RF models, which can likely be attributed to the lack of strong 455 linear predictors. Since RF can take advantage of a much larger group of predictor variables than 456 liner regression models, it is anticipated that RF coupled with a variable selection strategy would 457 result in a stronger predictive performance for stem density.

As noted earlier (Section 3.1), the combination of ALS and one optical sensor yielded 459 promising predictive accuracy for BA. Therefore, variables representing these predictor groups 460 were used to develop linear models of BA after variable selection. As can be seen from Table 4, 461 leaf-off spectral variables in the visible, red edge, and SWIR regions of the spectrum were the 462 most frequently selected for modelling BA, which corroborates well with the variable importance 463 scores reported in Figure 4. Notably, the red and NIR data derived from the leaf-off Landsat-5 TM 464 image in conjunction with a gap fraction measure (i.e., Percentage of first returns above 2m) 465 yielded a regression model with an $\mathrm{R}^{2}$ of 0.72 and $\mathrm{rRMSE}$ of $13 \%$. In a recent study that examined 466 the utility of Landsat 8 OLI (i.e., Operational Land Imager) imagery for modelling forest variables 467 for a Mediterranean forest, a significant relationship was also observed between field measured 468 BA and the visible and NIR bands of the OLI (Chrysafis et al., 2017). Among all the ALS metrics, 
this gap fraction metric has been consistently selected by all three hybrid BA models, due to its moderate positive correlation with BA. The three hybrid BA models featured comparable predictive accuracy, with the one containing ALS and WorldView-2 data performing marginally better than the rest (Figure 6). The slightly more pronounced scattering between the observed and predicted BA at higher ranges is likely a result of under-sampling in our field campaign. Due to the limited number of field plots with high BA values, the statistical relationship between BA and the predictor variables was not well established. Compared to the hybrid models, the ALS-only model had relatively poor predictive accuracy, with a $\mathrm{R}^{2}$ and rRMSE of 0.40 and 0.20 respectively.

Since spectral predictors derived from Sentinel-2A and WorldView-2 imagery exhibited strong predictive power for conifer RBA in diagnostic analysis, linear regression models were developed to examine whether the addition of ALS metrics could further improve the accuracy of the spectral models. The spectral models based on multi-seasonal Sentinel-2A and WorldView-2 imagery achieved a $\mathrm{R}^{2}$ of 0.81 and 0.85 respectively for modelling conifer RBA, while the $\mathrm{R}^{2}$ increased to 0.88 and 0.90 respectively for the corresponding hybrid models (Table 4). For modelling species mixture, the mean reflectance in the SWIR and red edge range of the spectrum proved to be the most useful predictors derived from Sentinel-2A. In comparison, the red edge and NIR bands were the most influential predictors from WorldView-2. It is worth noting that two out of four WorldView-2 predictors measure variability, rather than the average of reflectance at the plot level, giving rise to the strong utility of high spatial resolution imagery for modelling species abundance (Cho et al., 2012; Immitzer et al., 2012; Pu \& Landry, 2012). In contrast, all the Sentinel-2A variables selected for modelling conifer RBA represent mean reflectance at the plot level, likely a result of the lack of useful information in the texture variables derived from imagery of relatively coarse spatial resolution (i.e. $10 \sim 20$ m). Consequently, more ALS metrics (i.e., 3) 
were selected by the hybrid Sentinel-2A model compared to the case with the WorldView-2 hybrid model, containing only one intensity-based metric. Interestingly, this metric (i.e., mean intensity) was also selected by the Sentinel-2A hybrid model. Considering its low correlation with the spectral predictors in both hybrid models (i.e., VIF $<3$ ), mean intensity is deemed to carry critical information on species abundance (Heinzel \& Koch, 2011; Korpela et al., 2010; Kim et al., 2009), complementary to the contribution of spectral predictors derived from multispectral imagery. In accordance with a $\mathrm{R}^{2}$ of 0.90 associated with the best model for species mixture, a tight relationship was exhibited in the scatterplot between observed and predicted values (Figure 6). Despite the superior spatial resolution of the WorldView-2 imagery, the two hybrid models featured comparable accuracy, making the multi-seasonal Sentinel-2A imagery a viable option for assisting ALS-based forest inventories, especially considering the relatively high acquisition cost of WorldView-2 imagery.

When it comes to stem density modelling, hybrid models did not lead to significantly higher predictive accuracy than the ALS model (Table 4). In fact, the linear model taking advantage of both WorldView-2 predictors and ALS metrics was outperformed by the ALS model. Owing to the significant predictive power of multi-seasonal WorldView-2 imagery relative to the other two sensors, a linear model was developed using WorldView-2 predictors only, resulting in a moderate $\mathrm{R}^{2}$ of 0.59 . Spectral predictors selected for this model included mean and CV of spectral bands ranging from the visible to NIR regions of the spectrum. The utility of the NIR bands of WorldView-2 imagery for modelling stem density has been reported by Ozdemir \& Karnieli (2011). Earlier studies have also applied texture and shadow analysis to high spatial resolution imagery and obtained moderate accuracy for estimating stem density (Kayitakire et al., 2006; Couteron et al., 2005; Lévesque \& King, 2003). The ALS model for stem density utilized height 
515 and density metrics as well as three intensity-based metrics, corroborating the high variable 516 importance associated with these two types of ALS metrics for modelling stem density (Figure 4).

517 Figure 6 illustrates increased scatter (i.e., weaker correspondence) between the observed and 518 predicted stem density at larger ranges (i.e., the top quartile), which may be reduced with an 519 improved sampling strategy with greater focus on forest stands in early stand development stages. 
521 Table 4 Multiple linear regression models for BA, conifer RBA, and stem density. The $\mathrm{R}^{2}$ and 522 rRMSE values of the most accurate model for each response variable were highlighted in bold.

\begin{tabular}{|c|c|c|c|c|}
\hline $\begin{array}{l}\text { Forest } \\
\text { attributes }\end{array}$ & Predictor group & Selected variables & $\mathbf{R}^{2}$ & rRMSE \\
\hline \multirow[t]{4}{*}{ BA } & LiDAR & Elev.P95, Int.P80, D3, D8 & 0.40 & 0.20 \\
\hline & LiDAR + Sentinel-2A & $\begin{array}{c}\text { S2A_Aug_B7_mean, } \\
\text { Percentage.first.returns.above.2, } \\
\text { S2A_Mar_B11_mean, } \\
\text { S2A_Mar_B12_mean, S2A_Mar_B2_cv }\end{array}$ & 0.71 & 0.14 \\
\hline & LiDAR + WorldView-2 & $\begin{array}{c}\text { Wv_Jul_B8_mean, Wv_Nov_B5_mean, } \\
\text { Wv_Nov_B6_mean, } \\
\text { Percentage.first.returns.above.2, D1 }\end{array}$ & 0.73 & 0.13 \\
\hline & LiDAR + Landsat-5 TM & $\begin{array}{l}\text { Percentage.first.returns.above.2, } \\
\text { Lt5_Apr_B3_mean, Lt5_Apr_B4_mean }\end{array}$ & 0.72 & 0.14 \\
\hline \multirow[t]{4}{*}{$\begin{array}{l}\text { Conifer } \\
\text { RBA }\end{array}$} & Sentinel-2A & $\begin{array}{l}\text { S2A_Aug_B7_mean, } \\
\text { S2A_Mar_B11_mean, } \\
\text { S2A_Mar_B12_mean, } \\
\text { S2A_Mar_B7_mean }\end{array}$ & 0.81 & 0.33 \\
\hline & WorldView-2 & $\begin{array}{l}\text { Wv_Jul_B6_cv, Wv_Jul_B8_mean, } \\
\text { Wv_Nov_B6_mean, Wv_Nov_B8_cv }\end{array}$ & 0.85 & 0.30 \\
\hline & LiDAR + Sentinel-2A & $\begin{array}{c}\text { Int.mean, } \\
\text { Percentage.first.returns.above.2, D1, } \\
\text { S2A_Aug_B7_mean, } \\
\text { S2A_Mar_B11_mean, } \\
\text { S2A_Mar_B12_mean }\end{array}$ & 0.88 & 0.27 \\
\hline & LiDAR + WorldView-2 & $\begin{array}{c}\text { Int.mean, Wv_Jul_B6_cv, } \\
\text { Wv_Jul_B8_mean, Wv_Nov_B6_mean, } \\
\text { Wv_Nov_B8_cv }\end{array}$ & 0.90 & 0.25 \\
\hline \multirow[t]{4}{*}{$\begin{array}{l}\text { Stem } \\
\text { density }\end{array}$} & WorldView-2 & $\begin{array}{c}\text { Wv_Jul_B3_mean, Wv_Jul_B5_mean, } \\
\text { Wv_Jul_B8_mean, Wv_Nov_B1_cv, } \\
\text { Wv_Nov_B8_cv, } \\
\text { Wv_Jul_B6_cv }\end{array}$ & 0.59 & 0.27 \\
\hline & LiDAR & $\begin{array}{l}\text { Elev.P75, Int.stddev, } \\
\text { Int.kurtosis, Int.P90, D2 }\end{array}$ & 0.66 & 0.25 \\
\hline & LiDAR + Sentinel-2A & $\begin{array}{l}\text { Elev.MAD.median, Int.P25, Int.kurtosis, } \\
\text { Percentage.all.returns.above.mean, } \\
\text { S2A_Aug_B3_cv }\end{array}$ & 0.67 & 0.24 \\
\hline & LiDAR + WorldView-2 & $\begin{array}{c}\text { Wv_Jul_B2_mean, Wv_Jul_B6_cv, } \\
\text { Wv_Nov_B1_mean, Elev.P75, } \\
\text { Int.kurtosis, Int.P99 }\end{array}$ & 0.65 & 0.25 \\
\hline
\end{tabular}



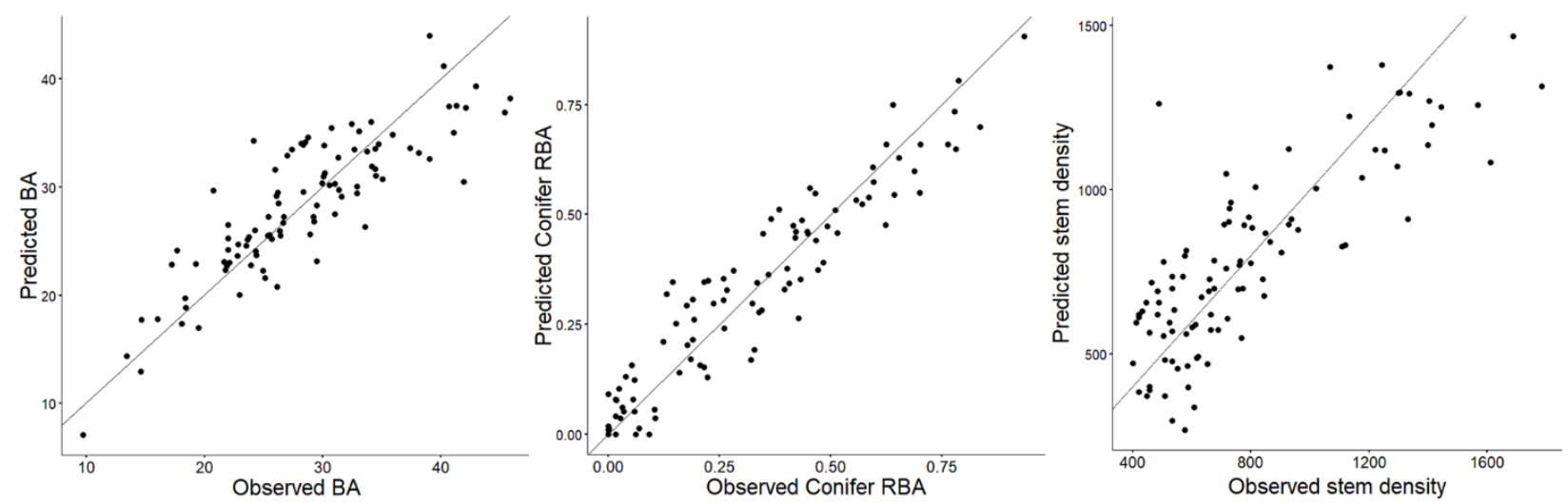

Figure 6 Scatterplots of the observed and predicted values derived from the best model for each forest inventory variable based on 10 -fold cross-validation.

\section{Conclusion}

This study assessed the potential of multi-seasonal multispectral imagery for assisting ALSbased forest inventory in an uneven-aged tolerant hardwood forest in Ontario, Canada. For BA, conifer RBA, and stem density, multi-seasonal image data generally exhibited stronger predictive performance than single date images. When multi-seasonal imagery is used in conjunction with ALS data, predictive accuracy was significantly improved for BA and conifer BA, while the accuracy of the stem density model was only marginally enhanced. Among the three sensors selected for comparison, WorldView-2 only slightly outperformed Sentinel-2A, despite its high acquisition cost and higher spatial resolution. Landsat-5 TM, on the other hand, had the overall lowest utility for modelling forest inventory variables, due to its coarser spatial and spectral resolution, as well as the lack of a red-edge feature. According to the variable dendrogram, multispectral imagery, ALS height and intensity data contain distinctive information regarding

539 forest structure. Despite the similar wavelengths, the correlation between ALS mean intensity and average NIR reflectance at the plot level is relatively low, indicating that they provide

541 complementary information for characterizing forest structure. Taking advantage of the two-step 
542 variable selection strategy, linear regression models outperformed RF models in terms of 543 predictive accuracy and ease of interpretation. Overall, the results of this study suggest that freely544 available multi-seasonal Sentinel-2A imagery holds great potential for enhancing ALS-based

545 forest inventories, especially after the application of an effective variable selection strategy.

\section{Acknowledgements}

547 Financial support for this research was provided by Natural Resources Canada (NRCan)

548 through an ecoENERGY Grant to the authors. The authors would also like to thank the Haliburton

549 Forest, Tembec Inc., MITACS, the Natural Science and Engineering Research Council (NSERC)

550 and Ontario Power Generation for their financial and logistical support of various components of

551 this research. Special thanks to Elaine Mallory, Jason Kerr, Michelle Bowman, and Gareth

552 Cockwell for their support in the field. 


\section{References}

Arii, K., Caspersen, J. P., Jones, T. A., \& Thomas, S. C. (2008). A selection harvesting algorithm for use in spatially explicit individual-based forest simulation models. Ecological modelling, 211(3), 251-266.

Belgiu, M., \& Drăguţ, L. (2016). Random forest in remote sensing: A review of applications and future directions. ISPRS Journal of Photogrammetry and Remote Sensing, 114, 24-31.

Bonan, G. B. (2008). Forests and climate change: forcings, feedbacks, and the climate benefits of forests. Science, 320(5882), 1444-1449.

Brandtberg, T. (2007). Classifying individual tree species under leaf-off and leaf-on conditions using airborne lidar. ISPRS Journal of Photogrammetry and Remote Sensing, 61(5), 325-340.

Breidenbach, J., Næsset, E., Lien, V., Gobakken, T., \& Solberg, S. (2010). Prediction of species specific forest inventory attributes using a nonparametric semi-individual tree crown approach based on fused airborne laser scanning and multispectral data. Remote Sensing of Environment, 114(4), 911-924.

Breiman, L. (2001). Random forests. Machine learning, 45(1), 5-32.

Breusch, T. S., \& Pagan, A. R. (1979). A simple test for heteroscedasticity and random coefficient variation. Econometrica: Journal of the Econometric Society, 1287-1294.

Budei, B. C., St-Onge, B., Hopkinson, C., \& Audet, F. A. (2017). Identifying the genus or species of individual trees using a three-wavelength airborne lidar system. Remote Sensing of Environment.

Chan, J. C. W., \& Paelinckx, D. (2008). Evaluation of Random Forest and Adaboost tree-based ensemble classification and spectral band selection for ecotope mapping using airborne hyperspectral imagery. Remote Sensing of Environment, 112(6), 2999-3011.

Chavent, M., Kuentz, V., Liquet, B., \& Saracco, L. (2011). ClustOfVar: an R package for the clustering of variables. arXiv preprint arXiv:1112.0295.

Chen, G., Hay, G. J., \& St-Onge, B. (2012). A GEOBIA framework to estimate forest parameters from lidar transects, Quickbird imagery and machine learning: A case study in Quebec, Canada. International Journal of Applied Earth Observation and Geoinformation, 15, 28-37.

Cho, M. A., Mathieu, R., Asner, G. P., Naidoo, L., van Aardt, J., Ramoelo, A., ... \& Erasmus, B. (2012). Mapping tree species composition in South African savannas using an integrated airborne spectral and LiDAR system. Remote Sensing of Environment, 125, 214-226.

Chrysafis, I., Mallinis, G., Gitas, I., \& Tsakiri-Strati, M. (2017). Estimating Mediterranean forest parameters using multi seasonal Landsat 8 OLI imagery and an ensemble learning method. Remote Sensing of Environment, 199, 154-166.

Cohen, W. B., Maiersperger, T. K., Gower, S. T., \& Turner, D. P. (2003). An improved strategy for regression of biophysical variables and Landsat ETM+ data. Remote Sensing of Environment, 84(4), 561-571.

Couteron, P., Pelissier, R., Nicolini, E. A., \& Paget, D. (2005). Predicting tropical forest stand structure parameters from Fourier transform of very high-resolution remotely sensed canopy images. Journal of applied ecology, 42(6), 1121-1128.

Culbert, P. D., Pidgeon, A. M., Louis, V. S., Bash, D., \& Radeloff, V. C. (2009). The impact of phenological variation on texture measures of remotely sensed imagery. IEEE Journal of Selected Topics in Applied Earth Observations and Remote Sensing, 2(4), 299-309.

Dalponte, M., Bruzzone, L., \& Gianelle, D. (2008). Fusion of hyperspectral and LIDAR remote sensing data for classification of complex forest areas. IEEE Transactions on Geoscience and Remote Sensing, 46(5), 1416-1427. 
Donoghue, D. N., Watt, P. J., Cox, N. J., \& Wilson, J. (2007). Remote sensing of species mixtures in conifer plantations using LiDAR height and intensity data. Remote Sensing of Environment, 110(4), 509-522.

Erdody, T. L., \& Moskal, L. M. (2010). Fusion of LiDAR and imagery for estimating forest canopy fuels. Remote Sensing of Environment, 114(4), 725-737.

Estornell, J., Ruiz, L. A., Velázquez-Martí, B., \& Hermosilla, T. (2012). Estimation of biomass and volume of shrub vegetation using LiDAR and spectral data in a Mediterranean environment. Biomass and bioenergy, 46, 710-721.

Falkowski, M. J., Wulder, M. A., White, J. C., \& Gillis, M. D. (2009). Supporting large-area, sample-based forest inventories with very high spatial resolution satellite imagery. Progress in Physical Geography, 33(3), 403-423.

Galelli, S., \& Castelletti, A. (2013). Tree-based iterative input variable selection for hydrological modeling. Water Resources Research, 49(7), 4295-4310.

García, M., Riaño, D., Chuvieco, E., \& Danson, F. M. (2010). Estimating biomass carbon stocks for a Mediterranean forest in central Spain using LiDAR height and intensity data. Remote Sensing of Environment, 114(4), 816-830.

Giri, C., Ochieng, E., Tieszen, L. L., Zhu, Z., Singh, A., Loveland, T., ... \& Duke, N. (2011). Status and distribution of mangrove forests of the world using earth observation satellite data. Global Ecology and Biogeography, 20(1), 154-159.

Gobakken, T., \& Næsset, E. (2004). Estimation of diameter and basal area distributions in coniferous forest by means of airborne laser scanner data. Scandinavian Journal of Forest Research, 19(6), 529-542.

Goward, S. N., \& Huemmrich, K. F. (1992). Vegetation canopy PAR absorptance and the normalized difference vegetation index: an assessment using the SAIL model. Remote sensing of environment, 39(2), 119-140.

Hansen, M. C., Potapov, P. V., Moore, R., Hancher, M., Turubanova, S., Tyukavina, A., ... \& Kommareddy, A. (2013). High-resolution global maps of 21st-century forest cover change. science, 342(6160), 850-853.

Heinzel, J., \& Koch, B. (2011). Exploring full-waveform LiDAR parameters for tree species classification. International Journal of Applied Earth Observation and Geoinformation, 13(1), 152-160.

Holmgren, J., \& Persson, Å. (2004). Identifying species of individual trees using airborne laser scanner. Remote Sensing of Environment, 90(4), 415-423.

Holmgren, J., Persson, Å., \& Söderman, U. (2008). Species identification of individual trees by combining high resolution LiDAR data with multi-spectral images. International Journal of Remote Sensing, 29(5), 1537-1552.

Hossain, S. M. Y., \& Caspersen, J. P. (2012). In-situ measurement of twig dieback and regrowth in mature Acer saccharum trees. Forest Ecology and Management, 270, 183-188.

Hubert, L., \& Arabie, P. (1985). Comparing partitions. Journal of classification, 2(1), 193-218.

Hudak, A. T., Crookston, N. L., Evans, J. S., Falkowski, M. J., Smith, A. M., Gessler, P. E., \& Morgan, P. (2006). Regression modeling and mapping of coniferous forest basal area and tree density from discrete-return lidar and multispectral satellite data. Canadian Journal of Remote Sensing, 32(2), 126-138.

Hudak, A. T., Crookston, N. L., Evans, J. S., Hall, D. E., \& Falkowski, M. J. (2008). Nearest neighbor imputation of species-level, plot-scale forest structure attributes from LiDAR data. Remote Sensing of Environment, 112(5), 2232-2245. 
Hyyppä, J., Hyyppä, H., Inkinen, M., Engdahl, M., Linko, S., \& Zhu, Y. H. (2000). Accuracy comparison of various remote sensing data sources in the retrieval of forest stand attributes. Forest Ecology and Management, 128(1), 109-120.

Immitzer, M., Atzberger, C., \& Koukal, T. (2012). Tree species classification with random forest using very high spatial resolution 8-band WorldView-2 satellite data. Remote Sensing, 4(9), 2661-2693.

Immitzer, M., Böck, S., Einzmann, K., Vuolo, F., Pinnel, N., Wallner, A., \& Atzberger, C. (2017). Fractional cover mapping of spruce and pine at 1 ha resolution combining very high and medium spatial resolution satellite imagery. Remote Sensing of Environment.

Karlson, M., Ostwald, M., Reese, H., Sanou, J., Tankoano, B., \& Mattsson, E. (2015). Mapping tree canopy cover and aboveground biomass in Sudano-Sahelian woodlands using Landsat 8 and random forest. Remote Sensing, 7(8), 10017-10041.

Kayitakire, F., Hamel, C., \& Defourny, P. (2006). Retrieving forest structure variables based on image texture analysis and IKONOS-2 imagery. Remote sensing of environment, 102(3), 390401.

Kim, S., McGaughey, R. J., Andersen, H. E., \& Schreuder, G. (2009). Tree species differentiation using intensity data derived from leaf-on and leaf-off airborne laser scanner data. Remote Sensing of Environment, 113(8), 1575-1586.

Koch, B. (2010). Status and future of laser scanning, synthetic aperture radar and hyperspectral remote sensing data for forest biomass assessment. ISPRS Journal of Photogrammetry and Remote Sensing, 65(6), 581-590.

Korpela, I., Ørka, H. O., Maltamo, M., Tokola, T., \& Hyyppä, J. (2010). Tree species classification using airborne LiDAR-effects of stand and tree parameters, downsizing of training set, intensity normalization, and sensor type. Silva Fennica, 44(2), 319-339.

Kuplich, T. M., Curran, P. J., \& Atkinson, P. M. (2005). Relating SAR image texture to the biomass of regenerating tropical forests. International Journal of Remote Sensing, 26(21), 4829-4854.

Laurin, G. V., Chen, Q., Lindsell, J. A., Coomes, D. A., Del Frate, F., Guerriero, L., ... \& Valentini, R. (2014). Above ground biomass estimation in an African tropical forest with lidar and hyperspectral data. ISPRS Journal of Photogrammetry and Remote Sensing, 89, 49-58.

Lévesque, J., \& King, D. J. (2003). Spatial analysis of radiometric fractions from high-resolution multispectral imagery for modelling individual tree crown and forest canopy structure and health. Remote Sensing of Environment, 84(4), 589-602.

Li, M., Im, J., \& Beier, C. (2013). Machine learning approaches for forest classification and change analysis using multi-temporal Landsat TM images over Huntington Wildlife Forest. GIScience \& remote sensing, 50(4), 361-384.

Liaw, A., \& Wiener, M. (2002). Classification and regression by randomForest. $R$ news, 2(3), 1822.

Liu, L., Coops, N. C., Aven, N. W., \& Pang, Y. (2017). Mapping urban tree species using integrated airborne hyperspectral and LiDAR remote sensing data. Remote Sensing of Environment, 200, 170-182.

Lim, K., Treitz, P., Wulder, M., St-Onge, B., \& Flood, M. (2003). LiDAR remote sensing of forest structure. Progress in Physical Geography, 27(1), 88-106.

Lopatin, J., Dolos, K., Hernández, H. J., Galleguillos, M., \& Fassnacht, F. E. (2016). Comparing generalized linear models and random forest to model vascular plant species richness using 
LiDAR data in a natural forest in central Chile. Remote sensing of environment, 173, 200210.

Masek, J. G., Vermote, E. F., Saleous, N. E., Wolfe, R., Hall, F. G., Huemmrich, K. F., ... \& Lim, T. K. (2006). A Landsat surface reflectance dataset for North America, 1990-2000. IEEE Geoscience and Remote Sensing Letters, 3(1), 68-72.

Maltamo, M., \& Gobakken, T. (2014). Predicting tree diameter distributions. In Forestry Applications of Airborne Laser Scanning (pp. 177-191). Springer Netherlands.

McRoberts, R. E., Cohen, W. B., Naesset, E., Stehman, S. V., \& Tomppo, E. O. (2010). Using remotely sensed data to construct and assess forest attribute maps and related spatial products. Scandinavian Journal of Forest Research, 25(4), 340-367.

Meroni, M., Colombo, R., \& Panigada, C. (2004). Inversion of a radiative transfer model with hyperspectral observations for LAI mapping in poplar plantations. Remote sensing of environment, 92(2), 195-206.

Mora, B., Wulder, M. A., White, J. C., \& Hobart, G. (2013). Modeling stand height, volume, and biomass from very high spatial resolution satellite imagery and samples of airborne LiDAR. Remote Sensing, 5(5), 2308-2326.

Mrosek, T., Balsillie, D., \& Schleifenbaum, P. (2006). Field testing of a criteria and indicators system for sustainable forest management at the local level. Case study results concerning the sustainability of the private forest Haliburton Forest and Wild Life Reserve in Ontario, Canada. Forest Policy and Economics, 8(6), 593-609.

Mutanga, O., Adam, E., \& Cho, M. A. (2012). High density biomass estimation for wetland vegetation using WorldView-2 imagery and random forest regression algorithm. International Journal of Applied Earth Observation and Geoinformation, 18, 399-406.

Naidoo, L., Cho, M. A., Mathieu, R., \& Asner, G. (2012). Classification of savanna tree species, in the Greater Kruger National Park region, by integrating hyperspectral and LiDAR data in a Random Forest data mining environment. ISPRS Journal of Photogrammetry and Remote Sensing, 69, 167-179.

Nicodemus, K. K., Malley, J. D., Strobl, C., \& Ziegler, A. (2010). The behaviour of random forest permutation-based variable importance measures under predictor correlation. BMC bioinformatics, 11(1), 110.

Oliveira, S., Oehler, F., San-Miguel-Ayanz, J., Camia, A., \& Pereira, J. M. (2012). Modeling spatial patterns of fire occurrence in Mediterranean Europe using Multiple Regression and Random Forest. Forest Ecology and Management, 275, 117-129.

Ozdemir, I., \& Karnieli, A. (2011). Predicting forest structural parameters using the image texture derived from WorldView-2 multispectral imagery in a dryland forest, Israel. International Journal of Applied Earth Observation and Geoinformation, 13(5), 701-710.

Packalén, P., \& Maltamo, M. (2007). The k-MSN method for the prediction of species-specific stand attributes using airborne laser scanning and aerial photographs. Remote sensing of Environment, 109(3), 328-341.

Pal, M. (2005). Random forest classifier for remote sensing classification. International Journal of Remote Sensing, 26(1), 217-222.

Pasher, J., \& King, D. J. (2010). Multivariate forest structure modelling and mapping using high resolution airborne imagery and topographic information. Remote Sensing of Environment, 114(8), 1718-1732. 
Penner, M., Pitt, D. G., \& Woods, M. E. (2013). Parametric vs. nonparametric LiDAR models for operational forest inventory in boreal Ontario. Canadian Journal of Remote Sensing, 39(5), 426-443.

Peterson, D. L., Aber, J. D., Matson, P. A., Card, D. H., Swanberg, N., Wessman, C., \& Spanner, M. (1988). Remote sensing of forest canopy and leaf biochemical contents. Remote Sensing of Environment, 24(1), 85-108.

Pitt, D., \& Pineau, J. (2009). Forest inventory research at the Canadian Wood Fibre Centre: Notes from a research coordination workshop, June 3-4, 2009, Pointe Claire, QC. The Forestry Chronicle, 85(6), 859-869.

$\mathrm{Pu}, \mathrm{R} ., \quad \&$ Landry, S. (2012). A comparative analysis of high spatial resolution IKONOS and WorldView-2 imagery for mapping urban tree species. Remote Sensing of Environment, 124, 516-533.

Puddister, D., Dominy, S. W. J., Baker, J. A., Morris, D. M., Maure, J., Rice, J. A., Jones, T.A., Majumdar, I., Hazlett, P.W., Titus, B.D., Fleming, R.L., \& Wetzel, S. (2011). Opportunities and challenges for Ontario's forest bioeconomy. The Forestry Chronicle, 87(04), 468-477.

Rodriguez-Galiano, V. F., Ghimire, B., Rogan, J., Chica-Olmo, M., \& Rigol-Sanchez, J. P. (2012). An assessment of the effectiveness of a random forest classifier for land-cover classification. ISPRS Journal of Photogrammetry and Remote Sensing, 67, 93-104.

Royston, J. P. (1982). Algorithm AS 181: the W test for normality. Journal of the Royal Statistical Society. Series C (Applied Statistics), 31(2), 176-180.

Sackett, T. E., Smith, S. M., \& Basiliko, N. (2012). Exotic earthworm distribution in a mixed-use northern temperate forest region: influence of disturbance type, development age, and soils. Canadian Journal of Forest Research, 42(2), 375-381.

Schlemmer, M., Gitelson, A., Schepers, J., Ferguson, R., Peng, Y., Shanahan, J., \& Rundquist, D. (2013). Remote estimation of nitrogen and chlorophyll contents in maize at leaf and canopy levels. International Journal of Applied Earth Observation and Geoinformation, 25, 47-54.

Shang, C., Treitz, P., Caspersen, J., \& Jones, T. (2017). Estimating stem diameter distributions in a management context for a tolerant hardwood forest using ALS height and intensity data. Canadian Journal of Remote Sensing, 43(1), 79-94.

Song, C. (2007). Estimating tree crown size with spatial information of high resolution optical remotely sensed imagery. International Journal of Remote Sensing, 28(15), 3305-3322.

St-Louis, V., Pidgeon, A. M., Clayton, M. K., Locke, B. A., Bash, D., \& Radeloff, V. C. (2009). Satellite image texture and a vegetation index predict avian biodiversity in the Chihuahuan Desert of New Mexico. Ecography, 32(3), 468-480.

Tonolli, S., Dalponte, M., Neteler, M., Rodeghiero, M., Vescovo, L., \& Gianelle, D. (2011). Fusion of airborne LiDAR and satellite multispectral data for the estimation of timber volume in the Southern Alps. Remote Sensing of Environment, 115(10), 2486-2498.

Vuolo, F., Żółtak, M., Pipitone, C., Zappa, L., Wenng, H., Immitzer, M., Weiss, M., Baret, F., \& Atzberger, C. (2016). Data service platform for Sentinel-2 surface reflectance and valueadded products: System use and examples. Remote Sensing, 8(11), 938.

Wehr, A., \& Lohr, U. (1999). Airborne laser scanning-an introduction and overview. ISPRS Journal of Photogrammetry and Remote Sensing, 54(2), 68-82.

White, J. C., Coops, N. C., Wulder, M. A., Vastaranta, M., Hilker, T., \& Tompalski, P. (2016). Remote sensing technologies for enhancing forest inventories: A review. Canadian Journal of Remote Sensing, 42(5), 619-641. 
779 Woods, M., Lim, K., \& Treitz, P. (2008). Predicting forest stand variables from LiDAR data in the Great Lakes - St. Lawrence forest of Ontario. Forestry Chronicle, 84(6), 827-839. Operational implementation of a LiDAR inventory in Boreal Ontario. Forestry Chronicle, 87(4), 512-528.

Wulder, M. A., Kurz, W. A., \& Gillis, M. (2004). National level forest monitoring and modeling in Canada. Progress in Planning, 61(4), 365-381.

$\mathrm{Xu}, \mathrm{C}$., Morgenroth, J., \& Manley, B. (2015). Integrating data from discrete return airborne LiDAR and optical sensors to enhance the accuracy of forest description: A review. Current Forestry Reports, 1(3), 206-219.

Zhu, X., \& Liu, D. (2014). Accurate mapping of forest types using dense seasonal Landsat timeseries. ISPRS Journal of Photogrammetry and Remote Sensing, 96, 1-11.

Zhu, Z., Jia, S., He, S., Sun, Y., Ji, Z., \& Shen, L. (2015). Three-dimensional Gabor feature extraction for hyperspectral imagery classification using a memetic framework. Information Sciences, 298, 274-287. 